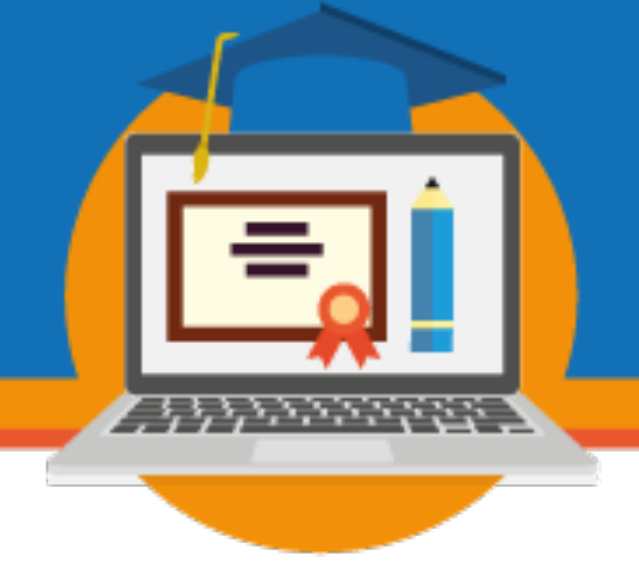

\title{
ENSINO HÍBRIDO NO ENSINO SUPERIOR: DESAFIOS DO TRABALHO DOCENTE
}

\author{
Eloane Aparecida Rodrigues Carvalho \\ Faculdade Una de Catalão/GO \\ eloane rodrigues@yahoo.com.br
}

\author{
Altina Abadia da Silva \\ Universidade Federal de Catalão/GO \\ tina@wgo.com.br
}

\author{
Hugo Maciel de Carvalho \\ Unidade Integrada Sesi/Senai de Catalão/GO \\ hugomlc@hotmail.com
}

Eixo 5: Educação híbrida: uma tendência na educação superior

Resumo: Essa reflexão perpassa o ensino híbrido e seus desafios no trabalho docente no Ensino Superior como uma possibilidade para se pensar a realidade tanto de formação quanto de atuação docente perante o uso da TDICs no processo de ensino-aprendizagem. Em suma, essa temática é importante devido sua intensidade no processo educacional incentivada pelo âmbito econômico e sociopolítico. Outrossim, aqui, evidencia discussões sobre o trabalho docente diante de formações acadêmicas que, a priori, visam experiências pautadas no ensino presencial e pouco vínculo as ferramentas tecnológicas, uma vez que nem todas instituições e alunos têm acesso ao mundo virtual como uma forma de aprendizagem. Por fim, essa pesquisa pautada em um levantamento bibliográfico com abordagem qualitativa visa problematizar e analisar os desafios entrelaçados nas potencialidades desse período tecnológico na qual a sociedade está inserida.

Palavras-chave: Educação Superior. Ensino Híbrido. Docente.

\section{Introdução}

O ensino híbrido é uma realidade em muitas instituições de Ensino Superior no Brasil, sobretudo em instituições particulares, pensar sobre essa questão requer destacar vários motivos que influenciam essa proposta de ensino. Aqui optamos em destacar duas possibilidades, de um lado, a integração de vários alunos de diferentes lugares em uma única plataforma sendo 


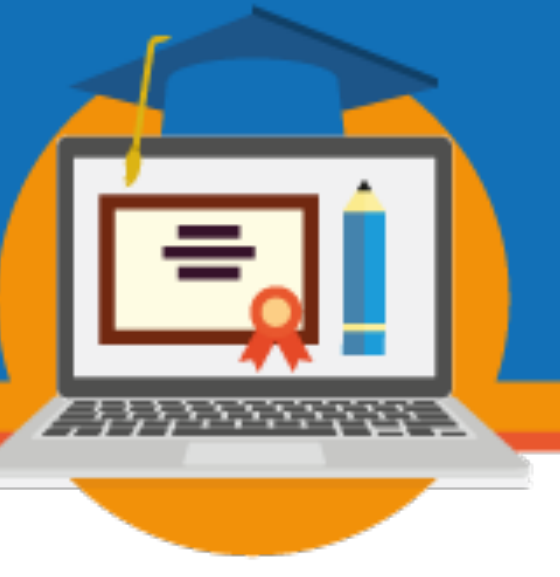

incumbida pela parte teórica do curso/disciplinas e a diminuição da carga horária presencial dos professores, uma vez que são responsáveis pela articulação da teoria com a prática.

Por outro lado, a necessidade em aproximar as formações de ensino superior ao uso das tecnologias se faz presente sobretudo por influência econômica que direciona o mundo do trabalho. Nesse sentido, os últimos anos, são marcados por avanços das tecnologias da informação e comunicação, as TDICs', principalmente no final do século XX e início do século XXI, na qual é considerado um período tecnológico direcionado pela globalização que exige novas dinâmicas social, política, econômica e ecológica.

Relacionar essa proposta de ensino híbrido no Ensino Superior se faz urgente e necessária uma vez que a presente realidade é marcada por essas interlocuções com o mundo "externo" a sala de aula. E nesse entremeio temos o professor e seu trabalho pedagógico sofrendo com o que era e o que se almeja ser, um fato que não se pode negar, é que os dilemas/possibilidades estão postos e influencia [in]diretamente o trabalho docente.

Portanto, nessa perspectiva, essa reflexão visa um breve levantamento conceitual do ensino híbrido e seus desafios para o trabalho docente no Ensino Superior a fim de compreender seu conceito, ao mesmo tempo que o coloque em "caixas" separadas do senso comum estabelecido para a interpretação de Educação a Distância.

\section{Ensino híbrido: breve levantamento conceitual}

O processo de ensino-aprendizagem no século XXI evoluiu, principalmente, com o crescimento da multimídia, os veículos de comunicação investem em documentos, vídeos, áudios, imagens e numerosos prospectos eletrônicos. Muitos desses podem ser obtidos usando a grande rede de computadores (internet), podem ser desenvolvidos de forma autoral e até

\footnotetext{
${ }^{1}$ Essa terminologia TDIC, segundo Daniel Mill (2012, p. 20) enfatiza as "tecnologias de base digital ou telemática (telecomunicações + informática". Além disso, para as pesquisadoras da função docente na EaD Juliana Cássia de Souza e Míriam Navarro de Castro Nunes (2012, p. 2), afirmam que "Na educação a distância (EaD), de modo diferente, professor e aluno podem nunca ter se visto, podem estar em diferentes lugares, e ainda assim, desenvolverem as atividades educativas. E essa é a proposta da educação a distância: a de inovar, trazendo ao universo tradicional escolar, as modernas Tecnologias da Informação (TDICs)".
}

III SEMINÁRIO DE EDUCAÇÃO A DISTÂNCIA

Diálogos sobre EaD e uso das TDIC na educação: regulamentação em tempos recentes 3 a 6 de novembro de 2020 - Brasília/DF - Online 


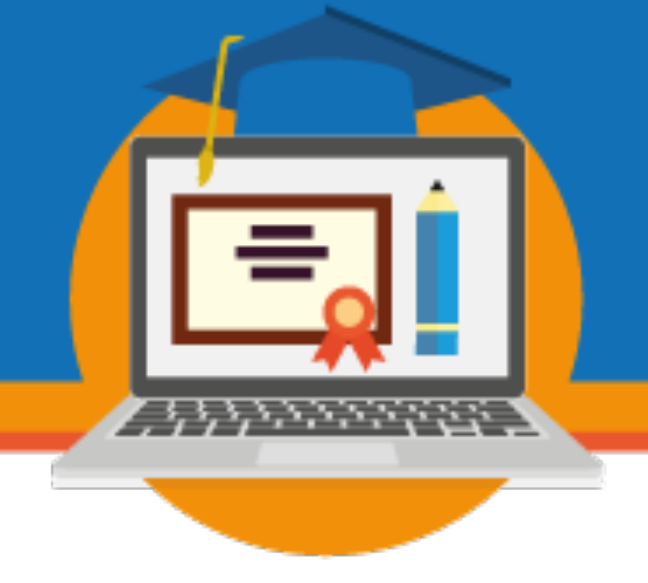

elaborados pelos alunos, usando a criatividade e a relevância para a proposta de desenvolvimento dos alunos.

Segundo Moran (2017, p. 2) "a tecnologia em rede e móvel e as competências digitais são componentes fundamentais de uma educação plena. Um aluno não conectado e sem o domínio digital perde importantes chances de informar-se, de acessar materiais muito ricos disponíveis [...]", além disso influencia no ato de comunicar-se, de se tornar visível para os demais, bem como de publicar suas ideias e aumentar sua empregabilidade futura. Essa perspectiva enaltece a ideia que a inserção das tecnologias tem um viés econômico e sociopolítico e que a educação tornou um elemento fundamental para dispersar os usos de tecnologias e suas funcionalidades no mundo contemporâneo.

A presente pesquisa ao relacionar o ensino híbrido a formação e a atuação docente no início do século XXI, visa ponderar os conceitos de Educação a Distância e Ensino Híbrido, visto que apesar de ocorrerem por meios da TDIC, há a diferença entre a realização da aprendizagem totalmente autônoma, que é o caso da $\mathrm{EaD}$ e a aprendizagem usando a modalidade híbrida. Visto que a EaD

[...] se caracteriza, fundamentalmente, pela separação física (espaço-temporal) entre o aluno e o professor, bem como a intensificação do uso de tecnologias de informações e comunicação (especialmente as tecnologias digitais) como mediadora da relação ensino-aprendizagem (MILL, 2018, p. 200).

O pressuposto condiz que a aprendizagem a distância e híbrida tenham como ponto de partida as metodologias ativas, sendo que, na segunda, ao final de um período de estudo, há a interação presencial entre docente-discentes e discentes-discentes. Segundo Mill (2018, p. 442) a aprendizagem híbrida se trata de um modelo onde há o uso das TDIC para a realização de atividades, parte online e parte presenciais. O intuito é que o momento presencial seja marcado por discussões e esclarecimentos sobre os conteúdos e a aplicação prática. E ainda

Metodologias Ativas apontam um horizonte possível de ser alcançado, na direção do exercício de práticas comunicacionais, informacionais e politicossociais de formação em que as TIC contribuam para a visualização e o exercício formativo de vivências necessárias às exigências de um profissional do século XXI (NONATO, SALES, SARLY, 2019, p. 163).

\section{SEMINÁRIO DE EDUCAÇÃO A DISTÂNCIA}




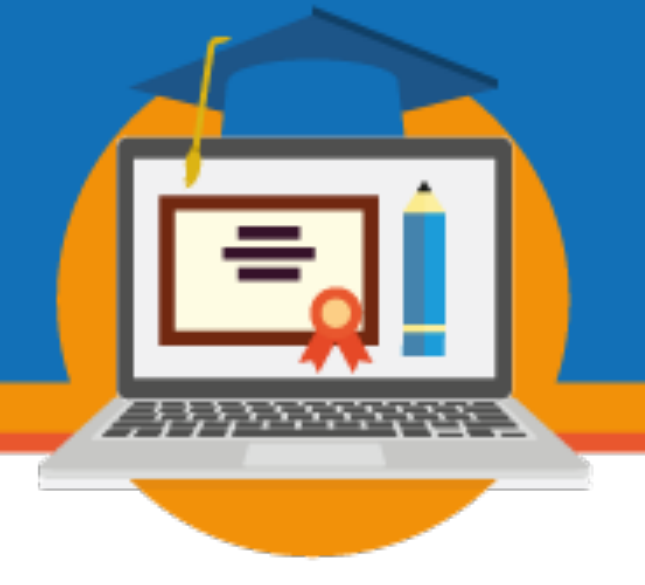

Em ambos os casos, se ressalta a importância entre a elaboração de conteúdos que permitam aos discentes a autonomia e a socialização com uma ferramenta que esteja ao seu alcance em qualquer lugar por meio da tecnologia. Em contrapartida a utilização de práticas inovadoras e desafiadoras que proponham aos alunos um conjunto de desafios e problemáticas interativas e interdependentes, por fim, a formulação de arranjos atrativos aos públicos distintos.

A proposta de diversificação de conteúdos online e presenciais envolve a capacidade desejável ao aluno ao final da aplicação do estudo proposto. Outrossim, a aprendizagem do aluno depende da qualidade do material desenvolvido, do tempo dispensado às leituras e compreensão dos conteúdos e a elaboração das atividades. Nesse caso, a modalidade híbrida visa a aplicação atividades individuais aliadas a atividades coletivas, visto que existe a possibilidade de interagir com os demais colegas e alunos.

Apesar dos diferentes conceitos, na Educação a Distância, no Ensino Híbrido ou nas Metodologias Ativas, a decisão sobre o andamento das atividades, sua gestão, relevância dos conteúdos e aprofundamento são decididos pelo discente, principalmente do discente adulto. Aos mais jovens ou idosos pode ser oferecido apoio ou acompanhamento especial até que eles consigam autogerir suas atividades de aprendizagem.

\section{Formação e atuação no Ensino Superior: reflexões sobre ser professor}

A presente pesquisa ao relacionar a formação e a atuação docente no início do século XXI, visa ponderar como se efetiva a atividade do professor do Ensino Superior Presencial diante do uso de novas tecnologias de base digital.É de suma importância reconhecer que essas inovações no âmbito da educação estão presentes em instituições tanto privada, como pública².

\footnotetext{
2 Segundo Libâneo (2012, p. 118), as universidades públicas, diante do avanço da Economia Neoliberal tornam-se ameaçadas e em permanente crise, pois "faltam recursos de toda ordem para garantir sua funcionalidade. 0 discurso neoliberal de Mercado questiona até mesmo a relevância social delas, ao mesmo tempo que vincula sua autonomia à questão do autofinancimento e da privatização, como única forma de sair da crise e alcançar competitividade, racionalidade, qualidade e eficiência".
}

III SEMINÁRIO DE EDUCAÇÃO A DISTÂNCIA

Diálogos sobre EaD e uso das TDIC na educação: regulamentação em tempos recentes 3 a 6 de novembro de 2020 - Brasília/DF - Online 


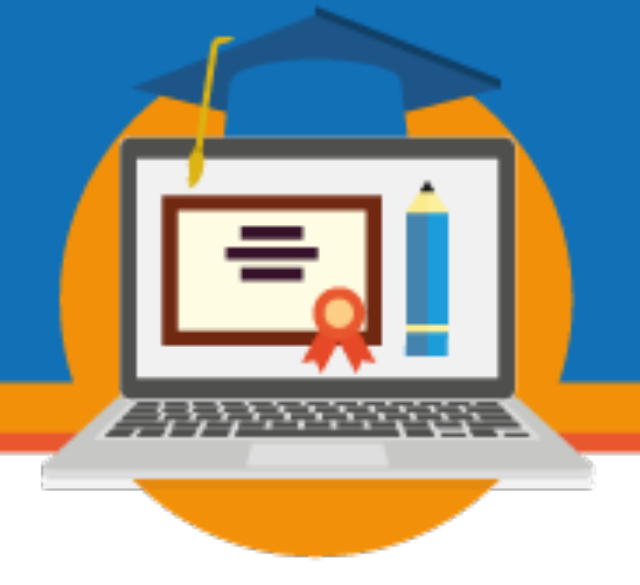

Para Chauí (2003) e o Libâneo (2012) essa flexibilização decorre das novas propostas de mercado global, nesse caso, econômico que tende a propiciar na maioria das vezes sua permanência na sociedade, bem como em alguns contextos, desenvolvimentos ou retrocessos.

Os discursos são múltiplos, e perpassam ora a partir de fatores positivos, ora negativos sobre o uso da TDIC no Ensino Superior Presencial ao passo que são inseridos e pouco compreendidos. No entanto, ao abordar tal temática deve-se considerar que "a universidade, mais do que determinada pela estrutura da sociedade e do Estado, seria antes um reflexo deles" (CHAUÍ, 2003, p. 6).

Nesse sentido, é possível compreender um novo contexto sendo (re)elaborado, sobretudo quando o assunto é a formação e a atuação docente e as novas tecnologias. Libâneo (2012, p. 66) afirma que “o Brasil, vem implementando, desde os anos 90 do século XX, suas políticas econômicas e educacionais de ajuste, ou seja, diretrizes e medidas pelas quais o país se moderniza, adquire as condições de inserção no mundo globalizado e, ajusta às exigências da globalização da economia”. Além disso, é necessário considerar que

\begin{abstract}
estamos vivendo na atualidade um período especialmente agitado, de contínuas e variadas mudanças em todas as ordens da vida, convertendo-se a mudança em uma constante do momento; e inclusive, alguém poderia afirmar que o que há de mais seguro nesta mudança é a própria mudança, de maneira que a atitude flexível com a mudança é uma das ferramentas mais úteis para poder se manejar neste contexto (SUANNO; RAJADELL, 2012, p. 59).
\end{abstract}

Quando se afirma que há um processo de "mudanças em todas as ordens da vida" significa que a educação também está vivenciando transformações, sobretudo quando o assunto é sobre as atuações dos profissionais docentes. Isto é, [...] há lugar, no novo sistema produtivo, para o trabalhador cada vez mais polivalente, flexível, versátil, qualificado intelectual e tecnologicamente e capaz de submeter-se a um contínuo processo de aprendizagem (LIBÂNEO, 2012, p. 125).

\title{
Outrossim,
}

a apropriação das tecnologias digitais de informação e comunicação e seu uso inovador podem se iniciar, mas não se limitam ao uso de tecnologia ou mídias no processo de ensino e aprendizagem e não se encerram com a descoberta de novos contextos de sua utilização. Envolvem, nesse processo, a consciência do papel dos agentes como leitores críticos do mundo das tecnologias, o mundo digital, sua

\section{SEMINÁRIO DE EDUCAÇÃO A DISTÂNCIA}


inserção neste mundo e, ainda, a recontextualização de sua prática pedagógica e sua integração ao currículo (ALMEIDA; SILVA, 2012, p. 53).

Até então, os docentes eram formados para atuar apenas no presencial, isto é, corpo a corpo, na medida em que ampliar e aprofundar os conteúdos, correspondia como a sua real preocupação. Além disso, eram frutos de "uma política educacional de longo prazo que priorizava a formação de professores cultos em cursos de longa duração" (SCHEIBE, 2016, p. 21). Essa situação com o passar dos anos foi se (re)elaborando, principalmente no âmbito da atuação dos docentes, isto é, até então o foco era trabalhar de forma presencial e a longo prazo os conteúdos. Atualmente, novas conjunturas foram absorvidas, inclusive em formações com duração mais rápida e, em muitas ocasiões aliadas ao ensino virtual.

Nesse sentido, este cenário vem sendo alterado cada vez mais ao passo em que "a docência é entendida como transmissão rápida de conhecimentos, consignados em manuais de fácil leitura para os estudantes, de preferência ricos em ilustrações e com duplicata em CDROM" (CHAUÍ, 2003, p. 7). Aqui, compartilha-se da perspectiva de Lev Vygotsky, pois não é possível padronizar o ritmo do processo de conhecimento sem levar em consideração os aspectos sociais, políticos, econômicos e culturais que os discentes estão inseridos.

Entretanto, o intuito dessa pesquisa é refletir, inclusive, como o docente atua nesse novo contexto que valoriza as novas tecnologias como uma das possibilidades para a redemocratização do saber. O que se percebe em maior proporção são modelos tradicionais de ensino inseridos nas bases digitais, ou seja, ainda se valoriza questões objetivas e discursivas pouco reflexivas como a essência para a formação docente e/ou demais formações.

E, quando alguns profissionais se arriscam por meio das novas possibilidades de trabalho, nesse caso as plataformas virtuais são exemplos de modelos que exigem dos profissionais da educação, logo precisam aprender na prática, a partir de (re)elaborações das práticas docentes presenciais para o mundo virtual. O contexto atual, evidencia a importância das tecnologias digitais para facilitar o processo ensino-aprendizagem, porém é necessário formações adequadas para atuar com essas ferramentas, pois transferir os modelos tradicionais 


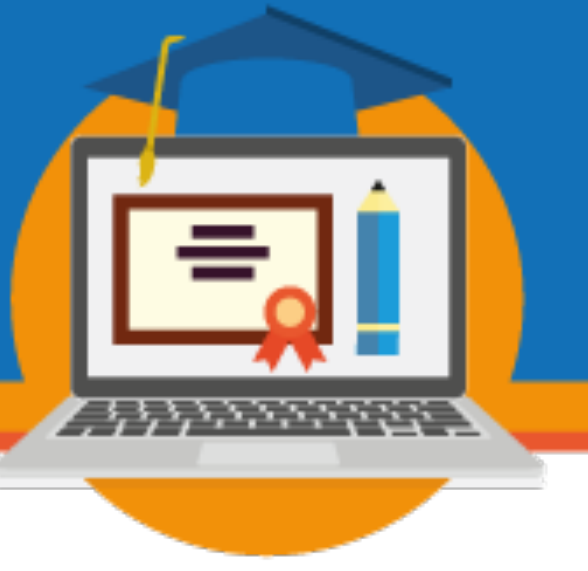

para as bases digitais não significa que o conhecimento e o novo contexto estão sendo ressignificados de forma efetiva.

Independente da proposta de ensino, isto é, virtual, presencial ou ambos é necessário que o docente atue de maneira eficaz e propicie um ensino-aprendizagem transformador ao passo que os discentes tenham possibilidade de intensificar e (re)elaborar o uso das novas bases digitais. É preciso levar em consideração que os processos de adaptações entre as práticas pedagógicas e o uso das tecnologias são de suma importância para que haja qualidade de ensino/aprendizagem, porém, precisa-se haver formações para essa nova conjuntura que configura o cenário atual.

\section{Considerações Finais}

O ensino híbrido se tornou uma realidade cada vez mais próximas das instituições de Ensino Superior, entre as possibilidades e desafios é preciso enaltecer que a cultura da população brasileira ainda não compreende a importância do mundo virtual vinculada às aulas presenciais, ou seja, ainda não consegue vivenciar essa nova forma de aprendizagem com pontos mais positivos do que negativos.

Aqui, buscamos pensar que por ser uma decisão além do professor, o ensino híbrido se faz e se fará cada vez mais intenso no âmbito da sala aula, ao passo que os desafios do trabalho docente se enaltecem quando o acesso é limitado, ou seja, não atende a todos e as possibilidades de práticas são pouco compartilhadas.

Por fim, infere-se que para o ensino híbrido pautado em dois ambientes de estudo, o engajamento e aproximação das aulas é prioritário uma vez que o distanciamento físico tanto no ambiente virtual quanto na aula presencial é recorrente. Buscamos pensar que uma possível pedagogia do abandono esteja cada mais distante e que seja compreendido a necessidade de integrar nas práticas pedagógicas elementos que relacionam com a vida dos sujeitos [acadêmico e profissional]. 


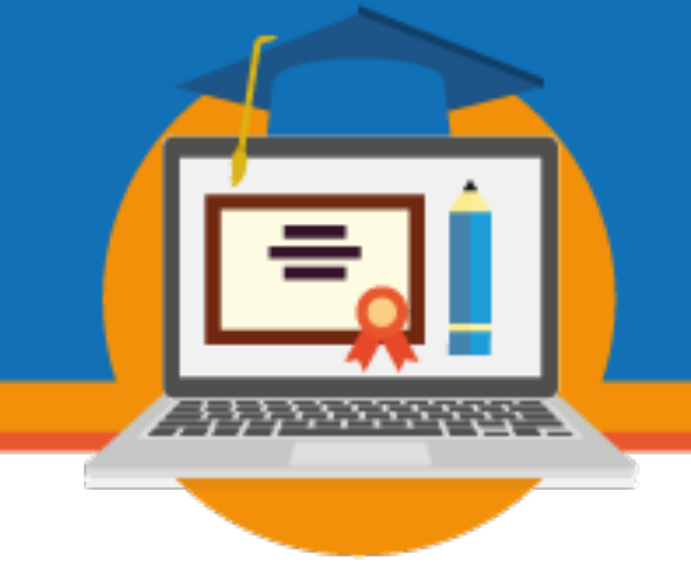

\section{Referências}

CHAUI, Marilena. A universidade pública sob nova perspectiva. Revista Brasileira de Educação. $\quad$ v. 24, 2003, p. 5-15. Disponível em: <http://www.scielo.br/pdf/rbedu/n24/n24a02.pdf>. Acesso em: 11 de maio de 2017.

LIBÂNEO, José Carlos. Educação escolar: políticas, estrutura e organização. 10 ed. (rev. e ampl.). São Paulo: Cortez, 2012. P. 31-56.

MORAN, José. Mudando a educação com metodologias ativas. In. SOUZA, C. A. e MORALES, O.E.T. (orgs.). Convergências midiáticas, educação e cidadania: aproximações jovens. Ponta Grossa: UEPG/Proex, pp. 15-33. Disponível em: http://www2.eca.usp.br/moran/wp-content/uploads/2013/12/metodologias_moran1.pdf.

Acesso em 15/02/2020.

MILL, Daniel. Docência virtual: uma visão crítica. Campinas, SP: Papirus, 2012.

MILL, Daniel. Dicionário crítico de educação e tecnologias e de educação a distância. Campinas, SP: Papirus, 2018.

NONATO, Emanuel do Rosário Santos; SALES, Mary Valda Souza; SARLY , Cezar Roberto. Educação a Distância, Hibridismo e Metodologias Ativas: Fundamentos conceituais para uma proposta de modelo pedagógico na oferta das disciplinas semipresenciais dos cursos presenciais de graduação da UNEB. EmRede Revista de Educação a Distância, 2019: 161-170.

SCHEIBE, Leda. Valorização dos profissionais de educação: a formação como foco. In. Valorização dos profissionais da educação: formação e condições de trabalho. Camaragibe. PE: CCS Gráfica e Editora, 2016. P. 13-30.

SILVA, Marco. Formação de professores para docência online. São Paulo: Edições Loyola, 2012.

SOUZA, Juliana Cássia de; NUNES, Míriam Navarro de Castro. Considerações acerca da função docente na Educação a Distância. SIED - Simpósio Internacional de Educação a Distância / EnPED - Encontro de Pesquisadores em Educação a Distância. Universidade Federal de São Carlos - UFSCar. 10 a 22 de setembro de 2012.10 p.

SUANNO, Marilza Vanessa Rosa; RAJADELL, Núria Puiggrós. Didática e formação de professores: perspectivas e inovações. Goiânia: CEPED Publicações e PUC Goiás, 2012. 


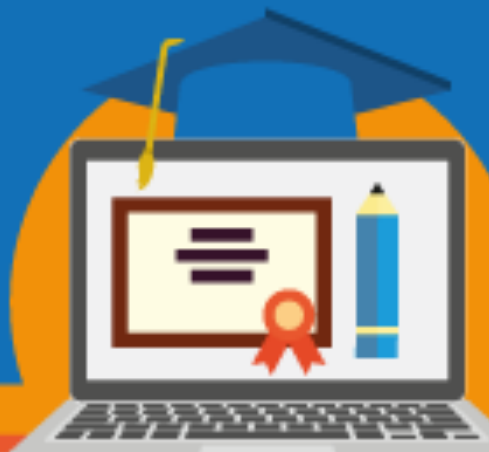

III SEMINÁRIO DE EDUCAÇÃO A DISTÂNCIA

Diálogos sobre EaD e uso das TDIC na educação: regulamentação em tempos recentes 3 a 6 de novembro de 2020 - Brasília/DF - Online 